\title{
(RE)ORGANIZAR O TRABALHO PEDAGÓGICO EM TEMPOS DE COVID-19: NO LIMIAR DO (IM)POSSÍVEL
}

\author{
Luana Costa Almeida ${ }^{1}$ \\ Adilson DALBEN ${ }^{2}$
}

\begin{abstract}
RESUMO: O artigo analisa a experiência de uma escola pública do estado do Paraná, Brasil, no início do enfrentamento dos desafios impostos pela pandemia da Covid-19. Examinaram-se os limites e as potencialidades do processo vivido pelos profissionais da escola durante a (re)organização de seu trabalho com a suspensão das atividades presenciais, ao mesmo tempo que vivenciavam a reestruturação das relações sociais com as incertezas e os riscos à vida. Desenvolvida como estudo de caso instrumental, a análise permite vislumbrar a potencialidade de reinvenção da escola, estimulada por processos participativos, não obstante os limites mediantes às condições objetivas dos envolvidos e das históricas mazelas dos sistemas educacional e social brasileiros, o que coloca a instituição trabalhando no limiar do (im)possível.
\end{abstract}

Palavras-chave: Covid-19. Gestão democrática. Organização do trabalho pedagógico.

\section{(RE)ORGANISING THE PEDAGOGICAL WORK IN TIMES OF COVID-19: ON THE THRESHOLD OF THE (IM)POSSIBLE}

\begin{abstract}
The article analyses the experience of a public school in the state of Paraná, Brazil, in the beginning of the challenges imposed by the COVID-19 pandemic. It examined the limits and potentialities of the process experienced by school professionals during the (re)organization of their work with the suspension of face-to-face activities, while experimenting the restructuring of social relations with the uncertainties and risks to life. Developed as an instrumental case study, the analysis allows us to glimpse the potentiality of reinventing the school, stimulated by participatory processes, notwithstanding the limits through the objective conditions of those involved and the historical evils of the Brazilian educational and social systems, which places the institution working at the threshold of the (im)possible.
\end{abstract}

Keywords: COVID-19. Democratic management. Pedagogical work organization.

1.Universidade Federal de São Carlos - Departamento de Teorias e Práticas Pedagógicas - São Carlos (SP), Brasil. E-mail: luanaca@ufscar.br

2.Universidade Estadual de Campinas - Laboratório de Observações e Estudos Descritivos - Campinas (SP), Brasil. E-mail: adilson.dalben@gmail.com 


\title{
(RE)ORGANIZAR EL TRABAJO PEDAGÓGICO EN TIEMPO DE COVID-19: EN EL LÍMITE DEL (IM)POSIBLE
}

\begin{abstract}
RESUMEN: El artículo analiza la experiencia de una escuela pública en el estado de Paraná, Brasil, en el marco del enfrentamiento de los desafíos impuestos por la pandemia de COVID-19. Examinó los límites y las potencialidades del proceso experimentado por los profesionales de la escuela durante la (re)organización de su trabajo frente la suspensión de las actividades presenciales, mientras vivenciaban la reestructuración de las relaciones sociales con incertidumbres y riesgos a la vida. Desarrollado como estudio de caso instrumental, el análisis permite vislumbrar el potencial de la escuela reinventarse, estimulada por procesos participativos, a pesar de todos los límites vividos debido a las condiciones objetivas de los involucrados y los problemas históricos de los sistemas educativo y social brasileños, lo que pone a la institución en funcionamiento en el límite del (im)posible.
\end{abstract}

Palabras-clave: COVID-19. Gestión democrática. Organización del trabajo pedagógico.

\section{Apresentação}

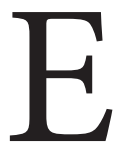

m março de 2020, instituiu-se a suspensão das atividades presenciais na rede estadual do Paraná, em decorrência da confirmação de casos do novo coronavírus (Sars-CoV-2) no Brasil, vírus esse que provoca a doença Covid-191 . Em meio à necessidade de (re)organização pedagógica da escola para atender às novas demandas e desafios, abriu-se uma potente oportunidade de compreender a resposta da instituição aos delineamentos contextuais impostos.

Como organização complexa, considerando-se o princípio da contradição, a escola possui diferentes formas de responder aos acontecimentos, mesmo delimitada por um aparato burocrático em que, geralmente, “o administrativo tem precedência sobre o pedagógico" (TRAGTENBERG, 2018, p. 189). Como a instituição tem vivido esse processo? Quais são os conhecimentos e recursos materiais que possui, ou deveria possuir, para que suas atividades possibilitem formas legítimas de ação? Diante da adoção do ensino remoto pelas redes, está a escola dando continuidade a um processo educacional ou exacerbando já conhecidos movimentos de desigualdade e exclusão?

Fruto de reflexão sobre contornos educacionais e evidências da experiência desenvolvida em uma escola pública do estado do Paraná, Brasil, em meio ao advento da pandemia, o presente artigo objetiva examinar contornos, limites e potencialidades do processo vivido pelos profissionais da escola diante da inevitável (re)organização de seu trabalho - reestruturação necessária, ao mesmo tempo que vivenciam, contextualmente, o risco à vida e a mudança nas relações sociais a partir do distanciamento social e do decorrente fechamento das escolas como meio de mitigação do contágio.

Respeitado o alerta feito por Santos (2020) sobre o lugar de análise dos estudiosos durante a pandemia, o movimento reflexivo proposto anda na esteira daquilo evidenciado pelos sujeitos partícipes da experiência. Buscou-se ouvir o que estava sendo dito e interpretar as ações tomadas para compreensão daquilo que podia ser evidenciado. 


\section{Contexto da Experiência: a Pandemia Envolve a Escola}

Com a declaração do estado de pandemia pela Organização Mundial da Saúde (OMS), em 11 de março de 2020, e a entrada do vírus no Brasil, em 13 de março, houve o primeiro anúncio de suspensão de atividades educacionais em território nacional, ação tomada pela Universidade Estadual de Campinas (Unicamp) e, dias depois, seguida por outras instituições do Ensino Superior e da Educação Básica.

Segundo a Organização das Nações Unidas para a Educação, a Ciência e a Cultura (UNESCO), em 16 de março, já eram cem países a anunciar a suspensão das atividades presencias nas escolas como medida de contenção do contágio, colocando o ensino remoto ${ }^{2}$ como alternativa para minimizar os efeitos indesejados da crise. No Brasil, o Ministério da Educação (MEC) constituiu um comitê para pensar a dimensão educacional na crise (BRASIL, 2020a), o qual atuou para a regulação da substituição de aulas presenciais por atividades em meio digital e para a flexibilização dos dias letivos, desde que mantida a carga horária mínima legalmente estipulada (BRASIL, 2020b; 2020c). Tal como ocorreu em outros estados, o Paraná, por meio da Deliberação n. 01/2020 (CEE/PR), autorizou a oferta de atividades não presenciais, com exceção à Educação Infantil ação referendada pelo Conselho Nacional de Educação (CNE) no Parecer CNE/CP n. 5/2020, homologado em $1^{\circ}$ de junho (BRASIL, 2020d), o qual ofereceu diretrizes, ainda que inconclusivas, para a reorganização do calendário escolar de 2020.

A favor da adesão ao ensino remoto está a aparente capilaridade do sistema digital, com acesso à Internet por dispositivos móveis como notebooks e smartphones. Mesmo viável sob mediação de diferentes meios (impresso, TV, rádio), podendo ocorrer de maneira síncrona, ao mesmo tempo, ou assíncrona, em horários diferentes, desde o início da comercialização mais ampla da Internet, seu principal formato tem sido o virtual online.

Presente em diferentes práticas sociais, a interação e a comunicação mediadas pelos recursos digitais são bastante difundidas e cada vez mais acessíveis, todavia não podemos nos furtar a reconhecer que ainda não estão democratizadas. Um exemplo disso pode ser notado na dificuldade de acesso e cadastro ao “apoio financeiro emergencial" de $\mathrm{R} \$ 600,00$ disponibilizado pelo governo brasileiro, o qual mostrou que as atividades digitais não são tão comuns e capilares como se poderia imaginar ${ }^{3}$.

Especificamente no campo educacional, o mesmo fenômeno ocorre em relação às políticas emergenciais adotadas, que esbarram em dificuldades diversas, entre as quais o acesso às plataformas digitais. Como evidencia a reportagem do G1 Educação de maio de 2020, "[n]o estado de SP, apenas 1,6 milhão dos 3,6 milhões de estudantes da rede estadual acessou a plataforma de conteúdo. No Paraná, professores estimam que só $30 \%$ dos estudantes estão assistindo às videoaulas e entregando as atividades propostas pelo aplicativo" (DOIS..., 2020).

Nas últimas décadas, embora o acesso e a permanência tenham se ampliado, a qualidade da oferta educacional tem sido prejudicada pela minimização dos investimentos em recursos humanos, materiais e de formação profissional (inicial e continuada). Uma das consequências da falta de financiamento público adequado é exatamente a não incorporação das tecnologias digitais nas práticas escolares, apesar do constante anúncio de suas potencialidades (MODELSKI; GIRAFFA; CASARTELLI, 2019).

A despeito de ser a única opção plausível, dadas as incertezas sobre a duração das medidas de isolamento, a implementação do ensino remoto se mostra via de mão dupla: por um lado, permite que o afastamento seja físico, mas não completo, com manutenção de contato social em meio virtual; por outro, traz, de maneira subjacente, o aumento das desigualdades educacionais já demasiadamente expressivas no sistema educacional brasileiro. Diante desse dilema, em contraponto a nada fazer, coube aos profissionais buscar formas de se reinventar para manter seu exercício docente. 
Como destacam Hodges et al. (2020, tradução nossa), as situações de crise requerem dos profissionais planejamento com solução criativa de problemas. Nas palavras dos autores, é preciso "[...] pensar fora dos padrões pré-formatados para gerar soluções viáveis que ajudem a atender às novas necessidades dos alunos e comunidades" (HODGES et al., 2020, tradução nossa). Esse fato exige redobrada atenção aos movimentos de precarização dos processos e do trabalho docente, já que o ensino remoto "exige planejamento e invenção, sim, mas uma educação de qualidade, salvo raras exceções, não se sustenta com improvisação”, como destacam Menezes et al. (2020).

Acompanhar o processo para compreender como os profissionais estão enfrentando os desafios dadas suas condições objetivas, subjetivas e intersubjetivas de trabalho, apresenta-se como caminho interessante: informativo do agora, é ação potencialmente promissora para alimentar estudos futuros.

\section{Contexto de Produção, Coleta e Análise dos Dados}

Os dados presentes neste trabalho se circunscrevem ao processo de recomposição escolar após unificação de duas escolas, o qual foi atravessado pelo advento da crise causada pela Covid-19. Eles foram coletados e sistematizados por um dos autores, que teve permissão para a pesquisa a partir da abertura possibilitada pela assessoria que prestava à escola, iniciada antes do advento da pandemia, com o propósito de apoiar os processos democráticos de gestão com ferramentas de planejamento e formação, auxiliados pela Avaliação Institucional Participativa (AIP) -recurso já experimentado em outros momentos e espaços (DALBEN, 2016) .

Após o processo de junção das unidades, a escola passou a atender mais de 1500 alunos matriculados em turmas de Ensinos Fundamental e Médio, além de três cursos profissionalizantes. Seu quadro funcional passou a ter aproximadamente cem professores, oito pedagogos, um diretor, dois diretores auxiliares e pouco menos de quarenta agentes educacionais, em atividades administrativas e de apoio.

No momento de suspensão das aulas presenciais, a gestão escolar estava em pleno processo de implementação das rotinas administrativas e de intervenção pedagógica apoiadas na gestão democrática. Para além das demandas burocráticas inerentes à gestão, a equipe estava empenhada em revitalizar os órgãos colegiados e aprimorar o Projeto Político Pedagógico (PPP) da escola, o qual seria alimentado com dados produzidos pela própria comunidade, a partir da implementação de processo de AIP na instituição.

Ao mesmo tempo que as demandas externas exigiram respostas da equipe para viabilização de atividades não presenciais na rede, especialmente aquelas mediadas por recursos digitais, intensificou-se a necessidade de acolhimento dos dramas sociais e emocionais desencadeados ou acirrados pela pandemia. Em reuniões realizadas já no primeiro dia do isolamento social, 17 de março, todos entenderam que, pela gravidade do momento, as ações e decisões para enfrentamento dos problemas seriam mais acertadas se ocorressem por meio de processos participativos de gestão democrática.

Diante do novo contexto, dada a intensificação das interações com a equipe escolar, viabilizou-se uma coleta intensa de dados, a qual permitiu a configuração do estudo de caso instrumental aqui apresentado. Como destaca André (2008), essa modalidade de pesquisa se caracteriza pelo interesse por uma questão que um caso particular pode ajudar a elucidar, sendo o foco das análises as revelações permitidas pela experiência.

Coletados entre os meses de março e maio de 2020, os dados são oriundos de documentos oficiais e de trabalho, registros de campo, observação e gravação em vídeo de reuniões de planejamento e grupos virtuais, assim como de dois questionários, um voltado aos docentes da escola e outro aos membros da equipe gestora. Seguindo as indicações constantes nas diretrizes éticas de pesquisa, foi solicitada autorização 
para coleta e divulgação das informações, incluindo-se apenas os sujeitos que explicitaram sua anuência. As gravações em vídeo foram autorizadas pelos participantes e, dos 79,6\% docentes que responderam ao questionário, 75,6\% autorizaram o uso dos dados para a pesquisa. Garantido o anonimato acordado, os respondentes são identificados, nos trechos transcritos, pela letra "E" seguida de número aleatório atribuído a cada um deles.

Aplicado virtualmente, o questionário foi composto por 29 questões, sendo quatro para respostas dissertativas e as demais objetivas. Já os dados provindos dos encontros virtuais são fruto de registro pessoal, em formato de diário de campo, e as gravações em vídeo tiveram partes transcritas, as quais compilam os principais temas abordados.

Para análise, as respostas objetivas dos questionários foram tabuladas e as questões abertas, assim como os registros em diário de campo e as gravações em vídeo, foram tratadas a partir da constituição de agrupamento por temas. Nos moldes propostos por Bardin (1977), efetivou-se uma primeira aproximação via leitura flutuante, passando à classificação por conteúdos que, posteriormente, foram agrupados em temáticas analíticas.

\section{Entre a Reinvenção e o Reconhecimento de Velhos Dilemas: Limites e Potencialidades Explicitados em Processo}

Iniciado em 6 de abril, com controle de frequência e notas, a implantação de ensino remoto pela Secretaria Estadual de Educação do Paraná (SEED-PR) foi muito célere. O ensino remoto proposto constitui-se basicamente pela disponibilização de aulas a ser assistidas e atividades a ser desenvolvidas pelos estudantes. As aulas são transmitidas pela televisão aberta e reproduzidas pela plataforma YouTube, e as atividades, disponibilizadas na plataforma Google Classroom e em meio impresso para aqueles sem acesso aos mecanismos digitais. As atividades virtuais são elaboradas, disponibilizadas, acompanhadas e controladas pela própria SEED e os professores têm como única opção manter, alterar ou complementar essas atividades. Convênios firmados possibilitaram que professores e alunos pudessem acessar a Internet sem custos financeiros pessoais.

Com sua celeridade justificada pela defesa do direito à aprendizagem, as ações propostas não foram inicialmente acompanhadas por políticas de formação ou por orientações que garantissem o acesso e o aprimoramento das interações entre alunos e professores - dimensão observada como importante em guias de enfrentamento à crise por Covid-19, por exemplo o elaborado pela Organização para a Cooperação e Desenvolvimento Econômico (OCDE, 2020).

Independentemente das ações e orientações orquestradas pela SEED, e contrariando a simples adoção da lógica burocrática, comum à organização escolar (TRAGTENBERG, 2018), a escola começou a refletir sobre seus processos, vislumbrando outras formas de ação. Apesar de o contexto conduzir para encaminhamentos mais prescritivos e burocráticos, a opção da direção no sentido de abarcar procedimentos eminentemente participativos se destacou, não apenas na delegação de reponsabilidades, mas, principalmente, na abertura para participação dos processos de decisão a partir do diálogo e da construção de alternativas, fazendo frente aos conhecidos processos de pseudoparticipação que objetivam legitimar a imposição verticalizada das decisões (FREITAS, 2005).

Diante da necessidade de manutenção do ensino remoto e pela observação da falta de acesso ao Classroom por muitos estudantes, a equipe gestora, em vez de se limitar às orientações oficiais da secretaria, decidiu mapear a questão a fim de ampliar o público participante. Com esse objetivo, um trabalho intenso 
começou a ser desenvolvido pelos pedagogos, profissionais ligados à gestão escolar, os quais também tinham dificuldades com os recursos tecnológicos, mas rapidamente as superaram no afã da construção desse trabalho.

Ao se iniciar a verificação dos acessos dos alunos de cada uma das turmas, em cada um dos componentes curriculares, observou-se que muitos dos professores também não estavam acessando ou simplesmente estavam deixando o processo fluir com as atividades publicadas pela SEED - aspecto que abriu em paralelo nova dimensão ao trabalho, visando motivar uma ação mais proativa desses profissionais, não voltada simplesmente ao cumprimento da demanda, mas ao compromisso com a aprendizagem dos estudantes.

Para o melhor monitoramento, a direção criou planilhas que, após serem compartilhadas na nuvem, foram preenchidas em tempo real pelos pedagogos, permitindo que os alunos sem acesso fossem facilmente identificados e, a partir disso, um intenso processo de estabelecimento de contatos se efetivasse. Nesse processo, os pedagogos começaram o contato com os estudantes e suas famílias por meio telefônico, pelas redes sociais digitais e por mensagens de WhatsApp.

Mesmo em meio à turbulência de ações, o resultado foi bastante satisfatório, culminando na rápida reversão do baixo número de acessos pelos alunos, como mostra o Gráfico 1 com dados que marcam o número de turmas dos Ensinos Fundamental e Médio que estavam em cada uma das faixas de acesso nas datas de 24 de abril, 4 de maio e 24 de maio 5 .

A Fig. 1 evidencia as possibilidades e limitações de atuação da escola na dimensão do acesso. Em 24 de abril, nenhuma das turmas tinha mais de 75\% dos acessos e, em 46,7\% delas, havia menos de 30\% de acesso. Após todo o empenho da equipe escolar, em 24 de maio, nenhuma turma tinha menos de $60 \%$ de acesso. Em $88,9 \%$ das turmas, havia mais de $60 \%$, sendo que, em $46,7 \%$ delas, o acesso ultrapassava $90 \%$. Além disso, das 21 turmas que estavam na faixa de acesso superior a $90 \%$, nove tinham $100 \%$ de seus alunos acessando. Nesse mesmo período, o valor médio de acessos dos alunos nas escolas pertencentes ao mesmo Núcleo da Superintendência de Educação Regional era de 44\%, segundo dados fornecidos pelo próprio núcleo. Trata-se de um significativo avanço, mas não suficiente, uma vez que os acessos médios da escola eram de $83,7 \%$, o que significava que $16,3 \%$ de seus estudantes permaneciam sem acesso.

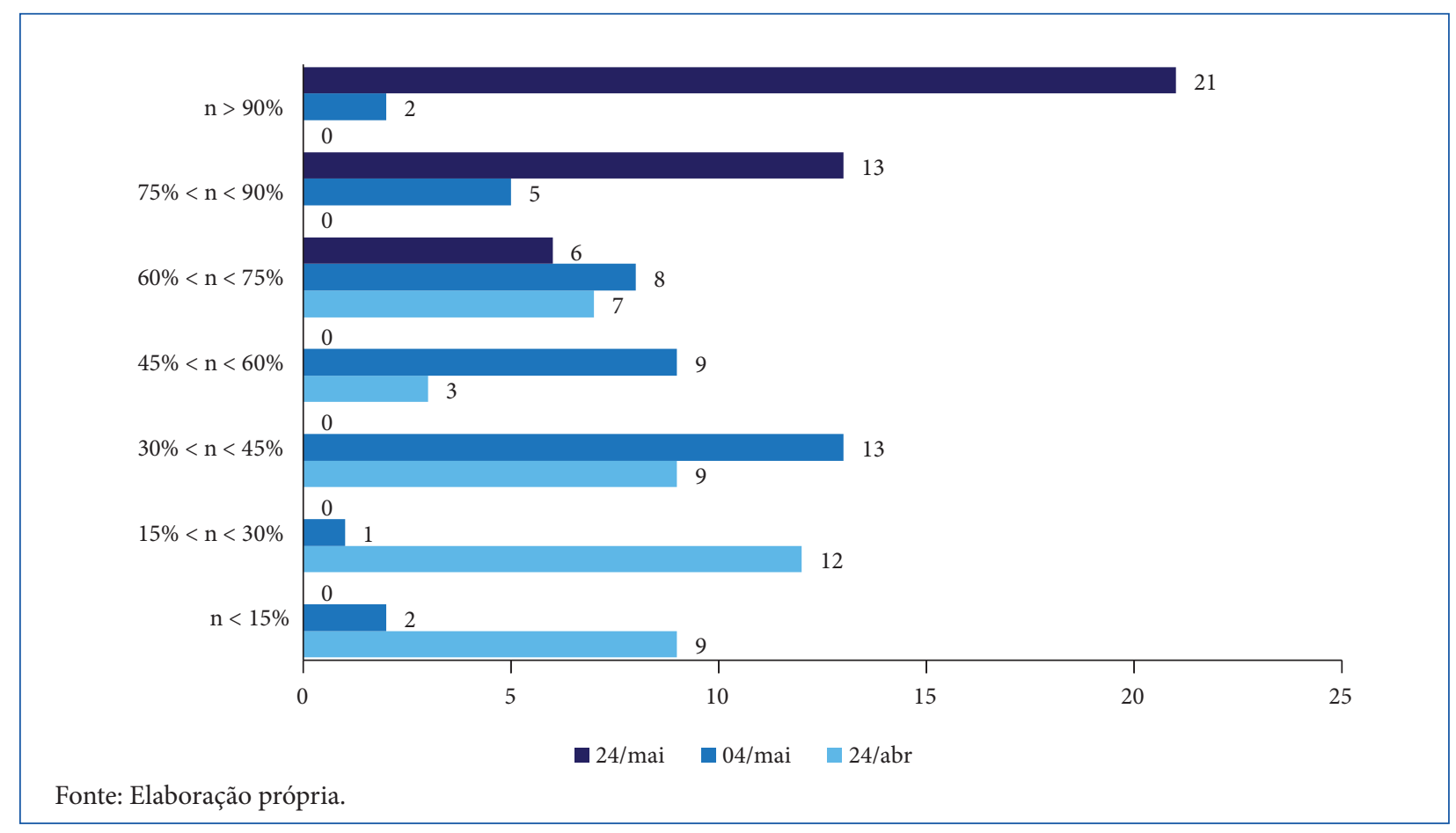

Figura 1. Porcentagem de acesso por turmas 
Em uma das reuniões do grupo, apesar do expressivo aumento nos acessos, foi proposto envolver os alunos do grêmio estudantil (um colegiado bastante ativo e presente na escola). Em projeto denominado "Conecta Escola", os alunos desenvolveram meios de comunicação multimidiáticos buscando que as informações chegassem a todos os estudantes e seus familiares.

A garantia das condições de acesso a todos os estudantes foge às possibilidades reais da escola. Muitas famílias não conseguem garantir a infraestrutura necessária para possibilitar a suas crianças e seus adolescentes o acompanhamento das atividades escolares, além de casos ainda mais severos, em que as condições objetivas de subsistência também estão comprometidas. Como destacam Pretto et al., na perspectiva das famílias de baixa renda, são múltiplas as questões postas, "destacando-se a inexistência de estrutura física e de conectividade domiciliar para que qualquer atividade de ensino remoto aconteça” (2020, p. 3).

Entendendo que, mesmo com limites, o trabalho para aumentar o número de acessos deveria continuar e se diversificar, foi estabelecida uma nova problematização pela equipe: o alto índice de acessos garante a aprendizagem dos alunos? A necessidade de reinvenção pedagógica das propostas se abriu como exigência das aprendizagens coletivas dos profissionais envolvidos para viabilizar alternativas mais potentes diante do novo contexto. Uma motivação adicional foi a convicção de que essas aprendizagens são importantes nesse momento, mas serão especialmente significativas para o contexto que se configurará após o isolamento social.

Contrariando assumir a ênfase no gerencialismo e na adoção da tecnologia como respostas prontas aos problemas enfrentados (FREITAS, 2012), a equipe gestora ousou construir outro caminho. Diante da situação instaurada e iminente a todo esse processo, além da manutenção do cumprimento das responsabilidades administrativas e de entrega de alimentos às famílias que necessitavam, a equipe passou a focar suas ações na reorganização das atividades, acolhendo as demandas e viabilizando apoio para a construção do melhor possível, mesmo com clareza de suas severas limitações - atitude reconhecida pela comunidade interna da escola, como destacado por diversos professores, ao externalizarem, nas questões abertas do questionário, a percepção de que, não apenas a direção tem se envolvido para que ações comprometidas com o trabalho dos professores e a aprendizagem dos estudantes aconteçam, mas também que sua atuação tem sido essencial para isso.

O contexto do colégio, penso que seja para todos. Vejo e elogio os esforços de todo o corpo do colégio para dar condições a professores e alunos neste momento crucial. Todos estão de parabéns (E17).

Tenho recebido muito suporte de toda a equipe de gestão e pedagógica nas dúvidas. Sou muito feliz em fazer parte dessa escola (E27).

Todos os professores estão interagindo na medida do possível. A diretora está socializando todas as informações e dúvidas nos grupos, disponibilizando materiais de pesquisa sobre as ferramentas de ensino para melhorar o entendimento e atendimento aos alunos e professores (E29).

$\mathrm{O}$ atendimento às demandas da SEED em meio à crise era inevitável, mas a escola iniciou um processo não deliberado de contrarregulação, ao buscar, em conjunto com a implementação dos recursos postulados, reinventar-se, almejando uma qualidade que não desprezasse o momento paradoxal em que todos viviam. De um lado, as questões emocionais e de vida inerentes à pandemia deveriam ser acolhidas e, de outro, havia a necessidade de viabilização de processos que permitissem a continuidade de um trabalho educacional, apesar do contexto inóspito e dos recursos inapropriados para a adoção de atividades pedagógicas mediadas pelo uso dos recursos digitais. 
Como destaca Freitas (2005), a contrarregulação ganha espaço e significado em meio a processos participativos nos quais não se exerce uma simples negação das orientações centrais, mas sua ressignificação via incrementação da qualidade do serviço público ofertado.

Contrarregulação é resistência propositiva que cria compromissos ancorados na comunidade mais avançada da escola (interna e externa), com vistas a que o serviço público se articule com seus usuários para, quando necessário, resistir à regulação (contrarregulação) e, quando possível, avançar tanto na sua organização como na prestação de serviços de melhor qualidade possível (justamente para os que mais têm necessidades), tendo como norte a convocação de todos para o processo de transformação social. [...] Isso porque nas políticas públicas neoliberais a mudança é vista como parte das ações gerenciais administradas desde um "centro pensante", técnico, ao passo que a tendência das participativas é gerar envolvimento na "ponta" do sistema. E é nos momentos em que o público é administrado por políticas participativas que se abre a possibilidade de incrementar tanto a qualidade do serviço público como a organização dos seus trabalhadores com o fim de criar condições para a contrarregulação (FREITAS, 2005, p. 912).

Vislumbrando um movimento ao mesmo tempo acolhedor e potencializador de aprendizagens, considerando que nem todos possuíam as habilidades necessárias para o uso das ferramentas digitais disponíveis, iniciou-se processo de formação dos sujeitos. De maneira dinâmica, foi-se instaurando um comportamento apelidado de "quem sabe mais ajuda quem sabe menos" e, na busca da conscientização de que acessos nas plataformas não deveriam ser compreendidos como aprendizagens efetivadas, foram abertas frentes de trabalho na escola. Via ferramentas digitais como WhatsApp, e-mail, Skype, Google Meet e lives por Facebook e YouTube, as frentes abarcaram desde o acolhimento pessoal até a reflexão sobre a implicação pedagógica das ações propostas, orientando-se basicamente em três dimensões:

- Manutenção do entusiasmo da equipe: voltada ao acolhimento das questões impostas pelo isolamento físico, incluindo temor pela saúde e pela vida, assim como do possível desinteresse dos alunos pelas tarefas propostas;

- Garantia do conhecimento minimamente necessário dos recursos digitais: voltada à necessidade de ampliação da interação entre alunos e professores com especial atenção ao uso dos recursos (quem, como e o que deve ser feito nos espaços virtuais);

- Reflexão sobre a qualidade das atividades em meio digital: voltada à busca de formas eficientes e efetivas de propiciar condições de aprendizagem para os alunos.

Para a manutenção do entusiasmo da equipe e o acolhimento aos envolvidos, foram criados e organizados grupos no aplicativo WhatsApp para que os pedagogos pudessem responder demandas relacionadas às manifestações de frustação. Além disso, encontros virtuais passaram a ser mais frequentes com a direção da escola, durante os quais eram acolhidas as questões pessoais e de contexto, além dos desafios pela falta de interação com os estudantes - ação importante e acertada se tomarmos análises como as contidas em Maia e Dias (2020), que, diante da intensificação de processos de ansiedade, depressão e estresse no contexto pandêmico, reiteram as recomendações de acolhimento aos sentimentos de tristeza e ansiedade, indicando a manutenção de redes sociais de apoio por meio das tecnologias de informação e comunicação. 
Na segunda dimensão, visando à garantia do conhecimento minimamente necessário dos recursos digitais, alguns professores com conhecimento mais desenvolvido na área tecnológica foram convidados para ajudar a pensar formas de atuação junto aos demais profissionais. Uma comissão formada por cinco professores e liderada por um dos diretores auxiliares, com participação de uma pedagoga, comissão essa autodenominada "Pensar EaD", passou a traçar políticas de formação para a equipe. Foram organizados encontros virtuais para essa formação, os quais, pela positividade de resultados, acabaram por tornar-se lives abarcadas pela superintendência regional, atingindo outras escolas da região.

Modelski, Giraffa e Casartelli (2019), ao investigarem a formação docente em tempos de cibercultura e sua inter-relação com conhecimentos, habilidades e atitudes para atuação de professores no cenário educacional influenciado pelo uso de tecnologias digitais (TD), revelam que nem sempre a fluência digital está presente entre os docentes. Os autores notaram que o nível de familiaridade com as TD está relacionado não apenas ao uso de artefatos, mas ao nível de experiência que se tem com eles.

Denominamos fluência digital a competência identificada no estudo, a qual está relacionada ao uso pedagógico de recursos tecnológicos para desempenhar atividades presenciais e virtuais, definida pela familiaridade com o uso de tais recursos e sua repercussão no planejamento docente. Ou seja, quanto mais fluência digital o professor desenvolve, mais facilidade ele pode ter para fazer associações entre as práticas que utiliza e uma eventual versão digital (MODELSKI; GIRAFFA; CASARTELLI, 2019, p. 8).

Importante destacar que uma das primeiras ações do "Pensar EaD” foi a elaboração de um questionário com o objetivo de diagnosticar o nível de letramento digital dos professores e pedagogos e, também, o nível de conhecimento dos recursos oferecidos pelo Classroom para melhor direcionar as propostas de formação. Como evidenciado na Fig. 2, as três categorias de respostas que geram maior preocupação foram apontadas por $81 \%$ dos professores. Além disso, dos $19 \%$ restantes, apenas menos da metade usava o Classroom com alguma frequência no ambiente escolar.

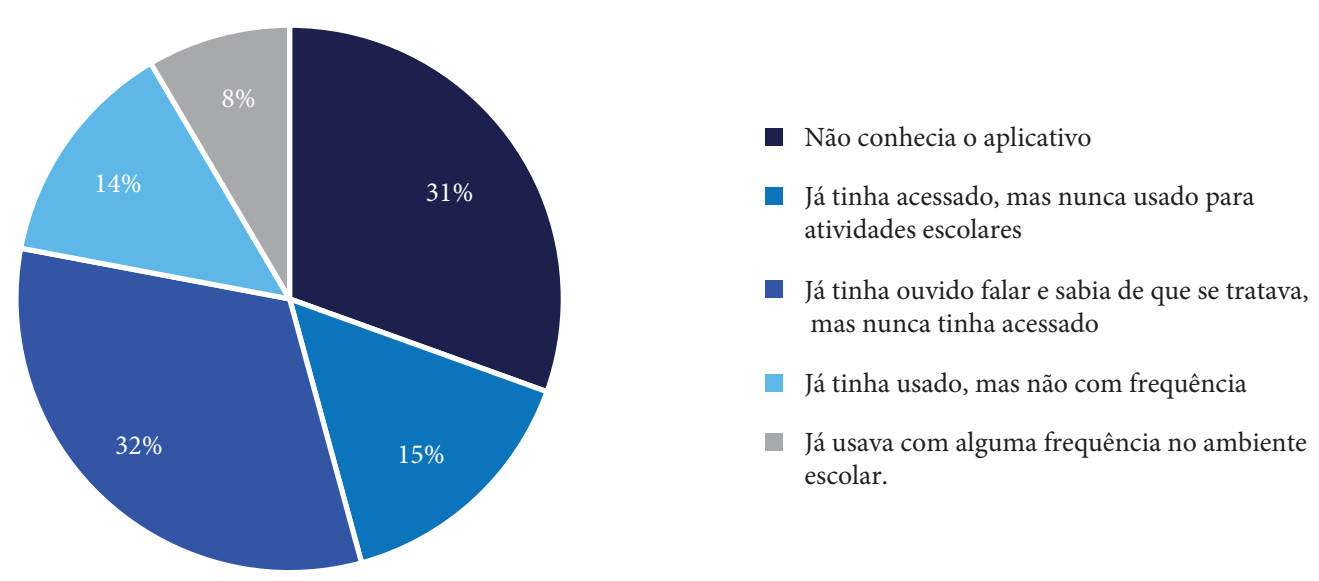

Fonte: Elaboração própria.

Figura 2. Familiaridade e acesso ao Classroom antes do isolamento social 
Pelas respostas ao questionário, os professores da escola foram classificados em quatro diferentes níveis: Nível 4 - Tem um amplo nível de conhecimento dos recursos do Classroom; Nível 3 Tem um adequado nível de conhecimento de alguns dos recursos do Classroom; Nível 2 - Tem alguns conhecimentos acerca dos recursos do Classroom; Nível 1 - Tem um frágil nível de conhecimento dos recursos do Classroom.

A partir disso, foi elaborada uma proposta para desenvolver o que foi chamado de "Aprendizagem Colaborativa", em que aqueles com maior domínio da ferramenta ajudariam os de menor domínio. A ação foi desenvolvida em forma de apadrinhamento, em que os professores de níveis mais elevados poderiam apadrinhar professores dos outros níveis. Alguns professores poderiam, portanto, ser padrinhos e apadrinhados ao mesmo tempo e era esperado que, após duas semanas, todos estivessem no Nível 4, condição para que a discussão deixasse de ser apenas acesso e passasse a ser a qualidade da oferta.

Como destacam Silva e Prata-Linhares, a percepção da falta de familiaridade no uso das tecnologias digitais de informação e comunicação (TDIC) na área educacional não é recente: “Dados da última pesquisa, realizada no ano de 2018, sobre o uso das Tecnologias da Informação e Comunicação nas escolas brasileiras, mostram o quanto ainda é preciso avançar em termos de acesso e finalidade pedagógica no uso das TDICs" (2020, p. 143).

Embora a fluência digital inicial dos professores fosse baixa, como vimos na Fig. 2, interessa evidenciar o movimento observado de envolvimento e busca de familiarização com as ferramentas. Como desvelado nos trechos transcritos a seguir, mesmo com sérias restrições, a percepção de avanço e satisfação tem sido notada.

Considerando que a situação da pandemia não é pontual, acredito que seja válida a tentativa de realizar uma proposta de $\mathrm{EaD}$ (embora nas condições em que foi implantada, naturalmente, necessite de muitos ajustes), pois possibilita que novas possibilidades sejam descobertas e desenvolvidas, aproveitando o tempo que seria perdido simplesmente por esperar os problemas desaparecerem. Todos estamos aprendendo muitas coisas neste momento (mais do que antes) (E14).

Está sendo uma nova maneira de ensinar. Aprendo um pouco a cada dia sobre as novas tecnologias e estou gostando. Sofrendo, mas ficando um pouco mais tecnológica (E21).

O processo está sendo necessário e inovador, pois aprender novas metodologias é importante para todos (E33).

Um aspecto importante a ser destacado nesse movimento empreendido pela escola é a dimensão coletiva da ação. Os "apadrinhamentos" permitiram um processo genuinamente coletivo e solidário para enfrentamento da falta de fluência digital entre os professores, garantindo o avanço do grupo como um todo - dimensão possivelmente potencializada pela maneira como se deu a organização para ação: participativa e não hierarquizada, em forma de trabalho conjunto. Como destacam Boy e Duarte (2014), ao retomarem conceitualmente a dimensão do trabalho coletivo, o trabalho em conjunto é uma forma de colaboração que permite a criação de interdependências mais fortes. No trabalho produzido coletivamente, há a corresponsabilização em processo, o empenho e o aperfeiçoamento dos coletivos, movimento que ainda gera como benefício a maior disponibilidade de envolvimento com as atividades de revisão e crítica do trabalho efetuado. 
Nessa mesma perspectiva, para Nóvoa, o compartilhamento de saberes entre os professores, em um trabalho efetivamente coletivo, como o vivenciado pela escola nessa experiência dos "apadrinhamentos", é uma forma de interação entre os profissionais que permite aplicar novas perspectivas e ferramentas teóricas e metodológicas. É um movimento que "[...] lhes permitem pôr em prática ideias e perspectivas que já aderem, mas que não sabem pôr em prática” (NÓVOA, 2004, p. 5).

Mobilizada pela exigência da Secretaria de Educação, mas animada pelo movimento mais acolhedor promovido na escola, a mudança na forma de responder às proposições se mostrou rapidamente. De modo dinâmico, e não pouco conflituosa, o movimento passou de uma negação inicial às propostas de uso dos recursos digitais para a discussão de suas ferramentas como possibilidade que tem suas potencialidades e limitações.

Na linha do que pontuam Menezes et al. (2020), não é possível compreender o que vem sendo praticado como educação on-line de qualidade, não apenas pela impossibilidade de entender de maneira linear o ensino remoto como educação a distância, mas também pela própria diversidade da situação de isolamento das pessoas, o que gera condições subjetivas e materiais muito diferentes, demandando mais que a simples tecnologia de "entrega" de conteúdos curriculares.

Essa preocupação está presente na escola e se manifesta na dimensão da reflexão sobre a qualidade das atividades em meio digital, na qual o debate construído passou a se voltar para o objetivo pedagógico considerando as condições objetivas de acesso e a finalidade pretendida. Os encontros virtuais e os dados provindos dos questionários evidenciam a reflexão dos envolvidos sobre os ganhos e as perdas que se tem com o processo.

Emergiu, entre os profissionais, a percepção sobre a necessidade de uma análise mais seriamente detida acerca da adaptação do que era previsto do presencial para o virtual, especialmente pelo receio de que o processo não promovesse a aprendizagem almejada. Em suas respostas, os docentes demonstraram consciência de que não se trata de mera transposição ao virtual, já que objetivos, metodologias e conteúdos devem ser seriamente analisados e adaptados às novas realidade e modalidade.

Acredito que o processo educacional tenha se tornado extremamente fragilizado, pois, além da dificuldade no uso das tecnologias, que muitos professores e alunos têm (apesar de esses últimos estarem habituados ao uso de certas tecnologias para interação social e lazer), também não se percebe que o protagonismo na Educação à Distância está "no aluno", não no professor (E6).

As aulas on-line, apesar de funcionarem, não apresentam o mesmo nível de possibilidades de ensino que as aulas presenciais (E8).

No técnico de enfermagem, a teoria e a prática andam juntas. No EaD, fica bem complicado. Entretanto estou fazendo o possível para assegurar o conhecimento (E31).

Corroborando essa percepção, alguns elementos trazidos por Wasserman, Holbert e Blikstein (2020), em artigo publicado originalmente no New York Daily News, destacam que a modalidade virtual exige aspectos que nem sempre estão presentes nos modelos assumidos atualmente. Segundo os autores, esses modelos acabam por representar ações superficiais, incapazes de oferecer experiências educacionais diversas, ricas e multimodais. 
[...] Embora os modelos on-line possam apoiar algumas dessas interações, eles são superficiais quando se trata de oferecer experiências educacionais diversas, ricas e multimodais. [...] O conhecimento não é transmitido, é construído quando colocamos nosso entendimento prévio em contato com novas ideias, experiências e ambientes. [...] o uso inicial da tecnologia tende a replicar as abordagens existentes, mas o potencial da nova tecnologia não está em manter o status quo, mas elevá-lo. [...] o uso da tecnologia não diminui tensões relacionadas à equidade na educação (WASSERMAN et al., 2020).

Contraditoriamente, as mesmas ferramentas capazes de mobilizar os professores a novas aprendizagens, a movimentos mais coletivos e solidários e potencialmente importantes para a continuidade do processo formativo dos estudantes, são aquelas que, ao não serem acessíveis a todos, aumentarão o fosso já bastante profundo das desigualdades. A falta de acesso pelos estudantes, a dificuldade enfrentada pelos professores e o medo de que muitos sejam deixados para trás durante o processo levam alguns profissionais a questionar a continuidade da proposta. Como destacado nos trechos transcritos a seguir, os respondentes questionam tanto a falta de acesso quanto a apropriação desigual das ferramentas e dos conteúdos pelos envolvidos.

Essa proposta em EaD não vai funcionar, pois a desigualdade social neste país é enorme e muitos alunos sequer têm o que comer, que dirá um celular bom com Internet para realizar essas atividades (E20).

Não sou contra o uso do Google Classroom ou o Aula Paraná. Mas, nesse momento, me preocupo com todos os meus alunos, mas principalmente com aqueles que já apresentavam muita dificuldade em sala de aula. Não acredito que estejam aprendendo alguma coisa (E26).

Para os alunos do Ensino Fundamental, está sendo de difícil acesso. Não está atingindo a todos (E35).

Essa modalidade de ensino está sendo legitimamente questionada pelas condições de acesso e corretamente criticada pela celeridade com que vem acontecendo. Ao mesmo tempo, os profissionais debatem os limites dessa modalidade e vão consolidando o que ela apresenta como potencialidade. Como destacam Modelski, Giraffa e Casartelli, a cultura digital necessária para a prática pedagógica é adquirida em processo e exige a vivência das experiências em uso: "Esta é a grande diferença: não são os artefatos digitais que permitem o estabelecimento da cultura digital que nos rodeia; a conexão em si é que oferta os desafios e possibilidades que nos desestabilizam e nos permitem reavaliar e pensar novas práticas" (2019, p. 13).

Em um movimento turbulento e desafiador, vão se manifestando dimensões inusitadas do novo. Concomitantemente ao desvelamento das dramáticas vivências do desafio profissional e das experiências pessoais em meio à pandemia, engendra-se a construção de alternativas, com rede de apoio mútuo e processos de trabalho conjunto, na busca pela construção de uma ação possível e produtiva. Como pode-se buscar em Freire (2011), em vários momentos, os condicionantes externos se impõem, mas não são assumidos como determinantes do trabalho. Opondo-se a uma resposta meramente burocrática, a escola ousou buscar uma (re)organização do trabalho pedagógico ao mesmo tempo comprometida com a aprendizagem dos estudantes e de seus profissionais e conhecedora dos severos limites que carrega. 


\section{Reflexões em Meio a Tudo: Atuando no Limiar do (Im)Possível}

Se não há como negarmos o rico processo que tem sido construído coletivamente pela escola graças à sua opção democrático-participativa, tampouco é possível ocultar a obsolescência em que muitos de seus processos se encontram ou a forma desigual com que os diferentes grupos acessam os bens e serviços disponíveis para o enfrentamento da crise. Sawaia, ao pensar sobre os impactos da Covid-19, chama atenção a como "um ser minúsculo, com capacidade desconcertante de disseminação, está impondo para as nossas vidas mudanças drásticas e em velocidade e abrangência global incomensuráveis" (2020). Ela desvela o que chama de "sofrimento ético-político": o sofrimento de quem entende e não aceita que a pandemia afete de forma desigual os já tão desiguais sujeitos sociais. Nada democrático, denuncia a autora, o encontro do vírus com os diferentes corpos passa, inevitavelmente, pela mediação das desigualdades sociais.

$\mathrm{Na}$ escola, isso é facilmente observável. Nem todos os estudantes têm acesso às alternativas adotadas pela rede. Muitos deles, além da falta de acesso instrumental aos meios digitais, convivem com a impossibilidade de manutenção das condições básicas de vida. A oferta de cestas básicas pela escola é insuficiente e apenas o fato de ser necessária já demonstra os severos limites de sua ação diante da realidade de algumas famílias. Sua ação inevitavelmente não abarcará a todos. Como reconhece a UNESCO de forma mais ampla,

[...] o fechamento das escolas acarreta altos custos sociais e econômicos para as pessoas nas comunidades. Seu impacto, porém, é particularmente severo para os meninos e meninas mais vulneráveis e marginalizados e suas famílias. As perturbações resultantes exacerbam as disparidades já existentes no sistema educacional, mas também em outros aspectos de suas vidas (2020b, tradução nossa).

Algumas falas evidenciam a percepção de que as condições apropriadas para acompanhamento das atividades propostas remotamente pela escola não estão presentes entre todos os estudantes. Como pode ser observado na fala do professor E20, já destacada anteriormente, a desigualdade e a falta de condições de subsistência são preocupações primordiais, mas, além delas, há também a falta de condições para o acompanhamento das atividades por parte dos estudantes, como destacou o professor E10 ao frisar a importância dos processos de mediação presencial:

É preciso ter clareza de que os alunos necessitam de acompanhamento presencial de alguém mais experiente no processo de ensino, que entendo ser a pessoa do professor [...] grande parte dos alunos não tem referência de um adulto no contexto familiar para realizar seus estudos (E10).

Os processos de vulnerabilidade social e os ativos que poderiam ser utilizados pelas famílias para o aproveitamento das oportunidades educacionais existentes são grave entrave para a ação educacional aos mais pobres. Isso porque, como discutido por autores como Kaztman (1999), Cunha (2006) e Stoco e Almeida (2011), estar em situação de vulnerabilidade social se refere à condição de não possuir ou não conseguir usar ativos materiais e imateriais que permitiriam lidar com a situação de pobreza e aproveitar as oportunidades disponíveis, entre elas as educacionais.

Não são questões que se abrem com a crise, mas que se manifestam nela de forma ainda mais aguda e explícita em função da maneira desigual com que afetam os diferentes grupos. Como exemplo, a diferença 
de possibilidade de acesso ao ensino remoto é severa. Segundo dados do Instituto Brasileiro de Geografia e Estatística (IBGE) ${ }^{7}$, os resultados da TIC Domicílios indicam que cerca de 30\% dos domicílios brasileiros não dispõem de Internet. Além disso, a principal tecnologia de acesso é o celular (97\%), sendo que 57\% dos domicílios não têm computador. Tais dados por si só colocam em estado de atenção as condições para atividades remotas, mas, somados às disparidades segundo classe de consumo, ficam ainda mais preocupantes, como pode ser observado na Fig. 3.

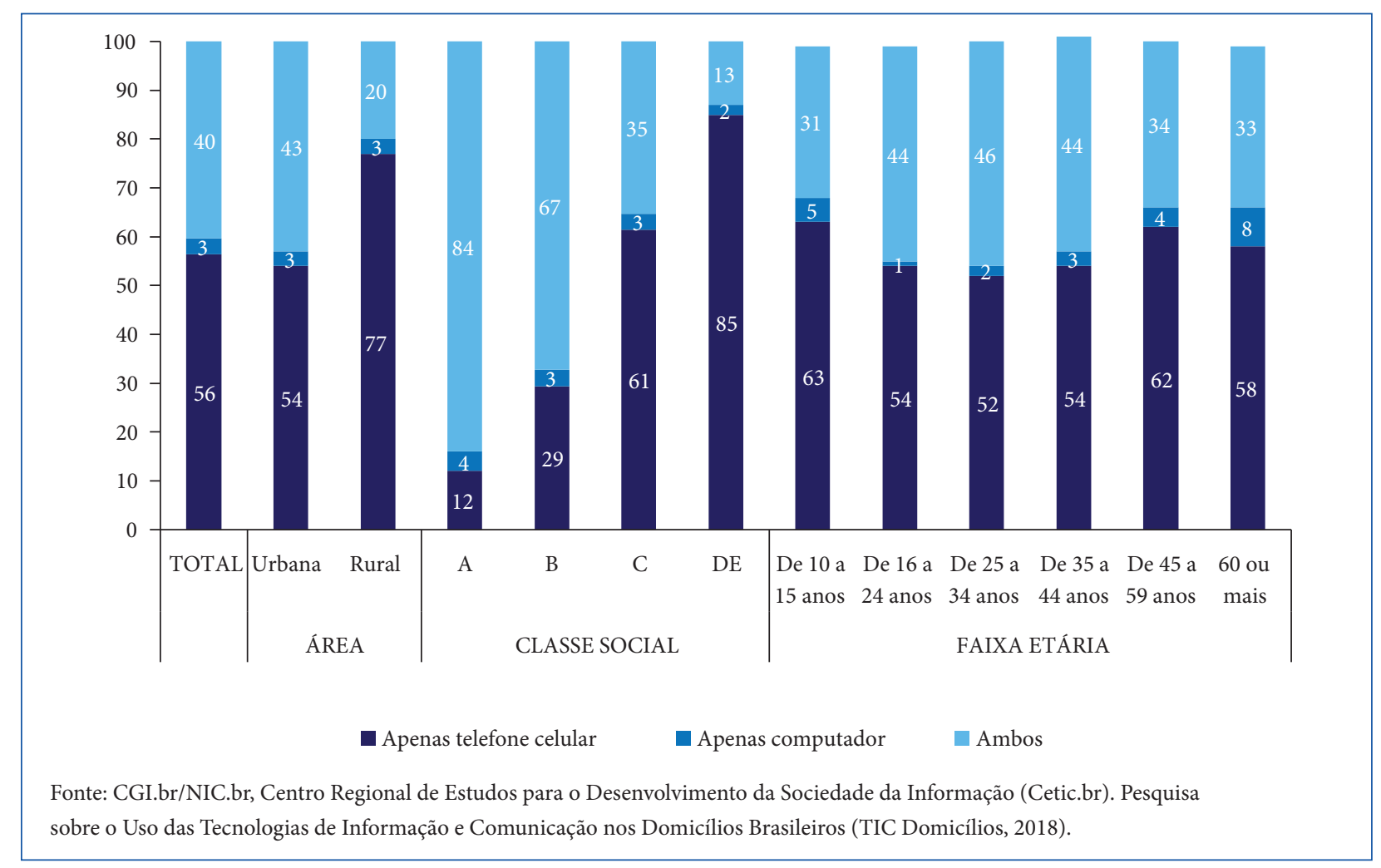

Figura 3. Usuários de Internet por dispositivo utilizado para acesso individual (\%).

Assim, os estudantes oriundos de famílias mais pobres tendem a ser os mais vulneráveis ao acúmulo de desvantagens no contexto da crise. Essa vulnerabilidade é observável nos dados apresentados, mas é visível na necessidade de oferta de cestas básicas pela escola, além de fatores como a falta de espaço apropriado para o desenvolvimento das tarefas e o aumento da violência doméstica observados pela UNESCO como consequências negativas da suspensão das atividades presenciais nas escolas (2020b). Esses fatores ampliam o fenômeno da desigualdade educacional, reverberando, como indicam Pretto et al., na possibilidade de acompanhamento das atividades remotas pelos diferentes grupos sociais.

Sem escolas, alunos de todas as idades e de todas as camadas sociais permanecem, teoricamente, em casa. Dizemos teoricamente, porque não podemos minimizar o debate a respeito das condições de habitação e de vida da população brasileira. Em um país com uma enorme desigualdade social, como o Brasil, é necessário especificar que essa casa, para as classes média e alta, se constitui numa edificação com diversos cômodos, que permite arranjos para o desenvolvimento de atividades individuais e coletivas; já para as classes populares, a casa é, muitas vezes, um único cômodo, onde convivem muitas pessoas, de pequenos a idosos, o que torna praticamente impossível permanecer nesse espaço o dia todo, ou desenvolver qualquer 
tipo de atividade que exija o mínimo de concentração e dedicação, como são geralmente aquelas ligadas à experiência educacional. [...] Portanto, as hashtags \#fiqueemcasa e \#aescolacontinua têm significados absolutamente diferentes para uma ou outra realidade, uma ou outra classe social (PRETTO et al., 2020, p. 2-3).

Adensando a complexidade do contexto em que se instaura o trabalho pedagógico em tempos de pandemia, das preocupações manifestas pelos profissionais, foram levantadas as difíceis condições de trabalho, o medo pela própria vida e pela vida dos que se ama e a necessidade de fazer mais e melhor pelos alunos, entendendo como faltantes os recursos básicos necessários. Como elucida de modo visceral o depoimento registrado pelo professor E7, não é simplesmente enfrentar uma dessas coisas por vez, mas vivenciar tudo isso reunido e misturado em um momento que desestabiliza e convida a repensar a vida e a profissão:

Apenas para que eu pudesse dizer e colocar para fora de mim que estou assustada e angustiada com o fato de ter que sair de minha zona de conforto. De pensar na mediocridade de algumas aulas que eu dei e do quanto eu poderia ter dado muito mais de mim quando eles estavam ali, na minha frente, ao alcance de minhas mãos, de meu olhar e do poder de minhas palavras. De ter que reconhecer minha ignorância e limitação quanto ao "mundo cibernético" e tecnológico. De ficar sem saber o que fazer quando a dúvida tem a dimensão do Oceano Atlântico. Quando eu tenho que ficar de madrugada procurando respostas em vídeos de profissionais no YouTube, [sendo que] de cada dez palavras que eles falam oito eu desconheço o significado. De ter que parar para cuidar dos que amo, preparando um alimento com gosto e sabor de amor por mais ruim que esteja, de limpar minha casa pensando nas coisas que vou postar no meu mural no Classroom, de pensar no filho que é médico veterinário e que sai todos os dias para trabalhar na área de saúde e no outro filho que está junto de mim tão angustiado quanto qualquer outro jovem de 20 anos [...]. De conversar diariamente com meu paizinho de 84 anos e minha mãezinha de 78 procurando enchê-los de esperança de que as coisas vão se resolver muito antes do que eles pensam e que muito em breve poderão rever e abraçar filhos e netos. De que esta professora tem vinte horas no estado e está trabalhando sessenta, apenas para não deixar que seus alunos tenham a impressão que ela não está nem aí com eles. E também para que eu tenha a oportunidade de dizer que eu acredito que, se colocarmos amor, respeito e seriedade profissional, isso vai dar certo sim, e nós faremos a diferença na educação com os alunos (E7).

Em tempos de isolamento social, para além da própria adoção dos recursos digitais, acompanhar o enfrentamento da pandemia em uma escola tem permitido ver que a (re)organização escolar necessária e exigida à instituição esbarra, para além das questões estruturais e pedagógicas, em uma avalanche de medos. Esses, múltiplos e intensos, são de natureza diversa e muito desafiadores: medo de não responder a contento às exigências tecnológicas; medo das desigualdades sociais; medo da doença; medo da morte.

Somado aos elementos que permitem compreender o movimento escolar em si e envolto à intensificação da desigualdade acarretada pelas escolhas políticas adotadas em meio à pandemia, emerge da análise o reconhecimento de que os processos democráticos ora iniciados se evidenciaram como peça importante para o enfrentamento inicial da crise pela escola, a qual tem atuado no que se pode chamar de limiar do (im)possível: um processo de (re)organização do trabalho pedagógico envolto pela vivência contextual de risco à vida e pela reestruturação das relações sociais decorrentes do isolamento social. 


\section{Considerações Finais}

Boaventura de Sousa Santos (2020), em A Cruel Pedagogia do Vírus, reflete sobre a oportunidade de se pensar a realidade e a qualidade das instituições em momentos de crise. Independentemente do que se evidencia como genuíno no contexto atual, fato interessante é notar que se explicitam e se amplificam várias questões já existentes, mas esquecidas ou ocultadas, no cotidiano das relações escolares.

Seja a desigualdade que adentra cotidianamente as escolas, seja a organização das ações, que demonstra graves sinais de incoerência com a realidade, o momento vivido e as exigências colocadas como horizonte pelas atuais determinações governamentais aprofundam um drama já conhecido dos professores, especialmente das redes públicas de ensino: como desenvolver o trabalho pedagógico a partir de realidades tão difíceis? Ou ainda, como denuncia, há tempos, Arroyo: como desenvolver um trabalho realmente potente diante da "[...] piora brutal das condições de viver a infância e a adolescência enquanto não melhoraram as condições de exercer a docência" (2014, p. 39)?

Em tempos de convivência com a Covid-19, mais que observar a construção de desigualdades e a procura por receitas fáceis às mazelas escolares no Brasil, vê-se a explicitação e o aprofundamento dessas. Em nome de uma alternativa tecnológica pouco afeita à igualdade de oportunidades, insensível ao momento histórico vivenciado por muitas famílias e não suficientemente desenvolvida para a utilização proposta pelos governos, muitos estão sendo abandonados, sejam eles professores, sejam estudantes.

Todo esse processo ainda está em curso; saber-se-á mais e melhor sobre seus limites e suas potencialidades a posteriori. Todavia, o já vivido permite engendrar inúmeras reflexões. Não obstante ser uma opção quase inevitável em contexto de impossibilidade de atividades presenciais, a implementação do ensino remoto se mostra complexa e desafiadora. Ao mesmo tempo que viabiliza o afastamento físico com manutenção de contato social por ambientes virtuais, aprofunda as já conhecidas desigualdades educacionais. Amplamente discutida e severamente criticada por suas consequências, essa alternativa foi adotada por diferentes redes e tem como marca uma diversidade de estratégias que podem resultar, em última instância, na efetivação de processos de exclusão.

Como política educacional proposta pelo governo e assumindo a necessária atenção ao que isso representa em relação a acesso e condições de aprendizagem e de trabalho docente, os processos participativos ora iniciados na escola estudada propiciaram um movimento mais potente. Além de atender de maneira burocrática o prescrito, o que foi considerado inevitável, a escola passou a se movimentar para tornar o mais efetivo possível seu trabalho, conhecendo e enfrentando as condições objetivas nas quais atua e buscando nas necessidades individuais o que era necessário para que o coletivo caminhasse.

Complementando a política pública, que orientou, de forma homogênea, as instituições da rede, iniciou-se localmente um processo de descortinamento dos problemas e de busca por soluções, ainda que com severos limites de ação. Apesar das regulações estatais fazerem a escola tender à adoção de processos prescritivos e burocráticos, contraditoriamente, ela passou a construir ações diversas para a inclusão dos diferentes sujeitos no processo. Esse movimento, com ações participativas e inclusivas, evidencia a necessidade de se tomar a escola como um locus pensante e com potencialidade para a mediação das políticas.

A problematização do uso dos recursos digitais e do ensino remoto foi um dos fatores centrais nesse processo. Historicamente associados a um ensino de menor qualidade que o presencial, a partir do questionamento sobre a qualidade das aprendizagens que possibilitam e dos severos processos de precarização do trabalho docente que fomentam em dependência do formato em que essa modalidade de ensino é adotada, muitas vezes se perdem, durante o debate, os benefícios que as ferramentas digitais podem trazer à educação como recurso didático. Nesse sentido, várias aprendizagens para o pós-pandemia ficarão. 
Tomando a escola como uma organização complexa, como convida Tragtenberg (2018), a análise do movimento desencadeado evidenciou uma prática pedagógica com dimensões inusitadas do novo, em que a inovação pedagógica requerida, assim como a complexa relação que possui com a dimensão didática do trabalho docente, revelou relações na escola e entre os sujeitos com potentes delineamentos para a reflexão dos momentos atual e futuro.

Ainda que submetida a processos de burocratização que desenvolvem certa despersonalização das relações, levando ao exercício seguro da impessoalidade que ignora os casos peculiares individuais (TRAGTENBERG, 2018), evidenciou-se na escola um processo de construção participativa de ações que buscaram a composição de um coletivo para pensar e enfrentar o momento de crise. Possível graças a processos democráticos iniciados anteriormente à suspensão das atividades presenciais, pode-se pensar nesse movimento como certa materialização rumo a um "inédito viável” (FREIRE, 2006). Mesmo sem a configuração de "atos-limite" que romperiam as "situações-limite" vivenciadas, as atitudes dos profissionais, entre si e em relação aos seus alunos e à gestão da rede, demonstram mobilização para enfrentamento da "situação-limite" localmente colocada.

Os homens e mulheres têm várias atitudes diante dessas "situações-limite": ou as percebem como um obstáculo que não podem transpor, ou como algo que não querem transpor ou ainda como algo que sabem que existe e que precisa ser rompido e então se empenham na sua superação (FREIRE, 2006, p. 205, grifos do autor).

Longe de uma análise que busca indicar o sucesso possível, mesmo em meio à crise, o que se destaca é o movimento inventivo e comprometido da escola, apesar de contexto tão devastador. Como indica Tragtenberg (2018), a organização escolar, regida pelo princípio da contradição, abarca a possibilidade de ir além da dramaturgia, a qual legitima na estrutura burocrática "o culto da aparência, dos gestos", em detrimento da inventividade possível aos profissionais avessos à realidade desigual.

A desigualdade, explicitada na crise, e a falta de processos de aprendizagem mais potentes via ensino remoto não serão resolvidas pela atuação empreendida pela escola, mas sua forma de (re)organização certamente dá outra possibilidade ao processo. É um acalento pequeno em meio ao experienciado, mas nem por isso menos potente. Se faz necessária uma investigação, mais aprofundada, para melhor compreender a experiência e aprender com ela. Todavia, adiante da demanda de continuidade da oferta educacional em meio ao risco à vida e à reestruturação das relações sociais, fato incontestável é que a escola tem atuado no limiar do (im)possível.

\section{Contribuição dos Autores}

Problematização e Conceituação: Almeida LC, Dalben A; Metodologia: Dalben A; Análise: Almeida LC; Dalben A; Redação: Almeida LC, Dalben A.

\section{Notas}

1. Segundo informações disponibilizadas pela Organização Pan-Americana da Saúde (OPAS), a Covid-19 é uma doença infecciosa causada pelo novo coronavírus, identificado pela primeira vez em dezembro de 2019, em Wuhan, na China. 
2. Devido a análises quanto ao inapropriado uso da expressão Educação a Distância (EAD) para as iniciativas propostas, passou-se a utilizar "ensino remoto". Como explicitam Hodges et al. (2020) o debate acerca da terminologia adequada às atividades remotas propostas em meio à crise é ponto importante de discussão e na comunidade acadêmica o "ensino remoto de emergência" surgiu como um termo alternativo usado para estabelecer um claro contraste com o que se conhece como EAD.

3. Diante de um controverso ambiente político, o governo federal brasileiro publicou, em edição extra do Diário Oficial da União ( 2 abr. 2020), a lei que cria um auxílio de R $\$ 600$ mensais, por três meses, a trabalhadores informais como uma das medidas de alívio à crise econômica provocada pela Covid-19. Para ter acesso ao benefício era necessário o cadastro por um aplicativo disponibilizado, o qual, todavia, gerou diversos níveis de dificuldade, muitos deles pela não familiaridade com a tecnologia utilizada.

4. Vinculada à Interação Urbana, uma empresa especializada em auxiliar organizações privadas na interface com o poder público, e inserida no Programa Klabin de Apoio ao Desenvolvimento Regional no Paraná, a assessoria tinha como propósito apoiar os processos democráticos de gestão da escola em momento de recomposição da instituição ocasionada pela unificação de duas unidades escolares.

5. As nove turmas dos cursos técnicos ainda não entraram nesse controle porque as turmas foram disponibilizadas somente entre os dias 27 de abril e 08 de maio.

6. O nome da instituição foi substituído por ESCOLA para mantermos o anonimato.

7. Disponível em: https://agenciadenoticias.ibge.gov.br/agencia-sala-de-imprensa/2013-agencia-de-noticias/releases/27515-pnadcontinua-tic-2018-internet-chega-a-79-1-dos-domicilios-do-pais. Acesso em: 6 maio 2020.

\section{Referências}

ANDRÉ, M. E. D. A. Estudo de caso em pesquisa e avaliação educacional. 3 ed. Brasília: Liber, 2008.

ARROYO, M. G. Imagens quebradas: trajetórias e tempos de alunos e mestres. Petrópolis: Vozes, 2014

BARDIN, L. Análise de Conteúdo. Lisboa: Edições 70, 1977.

BOY, L. C. G.; DUARTE, A. M. C. A dimensão coletiva do trabalho docente: uma experiência em duas escolas municipais de Belo Horizonte. Educação em Revista, Belo Horizonte, v. 30, n. 4, p. 81-104, 2014. https://doi. org/10.1590/S0102-46982014000400005

BRASIL. MEC. Portaria n. 329, de 11 de março de 2020. Institui o Comitê Operativo de Emergência do Ministério da Educação - COE/MEC. Diário Oficial da União: ed. 49, seção 1, Brasília, DF, 12 mar. 2020a.

BRASIL. MEC. Portaria n. 343, de 17 de março de 2020. Dispõe sobre a substituição de aulas presenciais por aulas em meios digitais enquanto durar a situação de pandemia do Novo Coronavírus - COVID-19. Diário Oficial da União: ed. 53, seção 1, Brasília, DF, 18 mar. 2020b.

BRASIL. MEC. Súmula do Parecer CNE/CP n. 5/2020. Reorganização do Calendário Escolar e da possibilidade de cômputo de atividades não presenciais para fins de cumprimento da carga horária mínima anual, em razão da Pandemia da COVID-19. Diário Oficial da União: ed. 83, seção 1, Brasília, DF, 4 maio 2020c.

BRASIL. MEC. Homologa parcialmente o Parecer CNE/CP n. 5/2020, do Conselho Pleno, do Conselho Nacional de Educação - CNE. Diário Oficial da União: ed. 103, seção 1, Brasília, DF, 1 jun. 2020d.

CUNHA, J. M. P. (org.). Novas metrópoles paulistas: população, vulnerabilidade e segregação. Campinas: Unicamp, 2006.

DALBEN, A. Caminhos da construção de uma Avaliação Institucional Participativa. Estudos em Avaliação Educacional, São Paulo, v. 27, n. 65, p. 346-374, 2016. https://doi.org/10.18222/eae.v0ix.3919 
DOIS meses após a suspensão de aulas presenciais, alunos, pais e professores relatam como está a educação durante a pandemia. Portal G1, [S. 1.], 22 maio 2020. G1 Educação. Disponível em: https://g1.globo.com/ educacao/noticia/2020/05/22/dois-meses-apos-a-suspensao-de-aulas-presenciais-alunos-pais-e-professoresrelatam-como-esta-a-educacao-durante-a-pandemia.ghtml. Acesso em: 22 maio 2020.

FREIRE, P. Pedagogia da esperança: um reencontro com a pedagogia do oprimido. 13. ed. São Paulo: Paz e Terra, 2006.

FREIRE, P. Pedagogia da autonomia: saberes necessários à prática educativa. 43. ed. São Paulo: Paz e Terra, 2011.

FREITAS, L. C. Qualidade negociada: avaliação e contrarregulação na escola pública. Educação \& Sociedade, Campinas, v. 26, n. 92 (n. especial), out. 2005. https://doi.org/10.1590/S0101-73302005000300010

FREITAS, L. C. Os reformadores empresariais da educação: da desmoralização do magistério à destruição do sistema público de educação. Educação \& Sociedade, Campinas, v. 33, n. 119, p. 379-404, 2012. https:// doi.org/10.1590/S0101-73302012000200004

HODGES, C. et al. The difference between emergency remote teaching and online learning. Educause Review, 27 mar. 2020. Disponível em: https://er.educause.edu/articles/2020/3/the-difference-betweenemergency-remote-teaching-and-online-learning. Acesso em: 4 jun. 2020.

KAZTMAN, R. (org.). Activos y estructuras de oportunidades: estudios sobre las raíces de la vulnerabilidad social en Uruguay. Montevideo: PNUD/CEPAL, 1999.

MAIA, B. R.; DIAS, P. C. Ansiedade, depressão e estresse em estudantes universitários: o impacto da COVID-19. EstudosdePsicologia,Campinas,v.37, e200067,p.1-8,2020.https://doi.org/10.1590/1982-0275202037e200067

MENEZES, C. et al. Artigo: educação a distância no contexto universitário. UFRGS, Porto Alegre, 24 abr. 2020. Disponível em: https://www.ufrgs.br/coronavirus/base/artigo-educacao-a-distancia-no-contextouniversitario/. Acesso em: 6 maio 2020.

MODELSKI, D.; GIRAFFA, L. M. M.; CASARTELLI, A. O. Tecnologias digitais, formação docente e práticas pedagógicas. Educação e Pesquisa, São Paulo, v. 45, e180201, 2019. https://doi.org/10.1590/ s1678-4634201945180201

NÓVOA, A. O professor, a escola e as mudanças educacionais - entrevista com professor António Nóvoa. Textos Reflexivos. São Paulo: GRUHBAS Projetos Educacionais e Culturais, 2004.

OCDE [ORGANISATION DE COOPÉRATION ET DE DÉVELOPPEMENT ÉCONOMIQUES]. A framework to guide an education response to the COVID-19 Pandemic of 2020. [S. 1.]: OCDE, 2020. Disponível em: https://www.hm.ee/sites/default/files/framework_guide_v1_002_harward.pdf. Acesso em: 4 jun. 2020.

PRETTO, N. D. L.; BONILLA, M. H. S.; SENA, I. P. F. S. Educação em tempos de pandemia: reflexões sobre as implicações do isolamento físico imposto pela Covid-19. Salvador: Edição do autor, 2020.

SANTOS, B. S. A cruel pedagogia do vírus. Coimbra: Edições Almedina, 2020.

SAWAIA, B. B. Apresentação. Expressões da pandemia. São Paulo: Núcleo de Pesquisa Dialética Exclusão/ Inclusão Social /PUC-SP/CNPq; Amazonas: Núcleo de Estudos e Pesquisas em Ambientes Amazônicos/ UFAm/CNPq, 2020. v. 1. 
SILVA, K. F.; PRATA-LINHARES, M. M. Tecnologias digitais de informação e comunicação e educação a distância na formação docente: qual inovação? Revista Educação e Políticas em Debate, Uberlândia, v. 9, n. 1, p. 137-150, jan.-abr., 2020. https://doi.org/10.14393/REPOD-v9n1a2020-54808

STOCO, S.; ALMEIDA, L. C. Escolas municipais de Campinas e vulnerabilidade sociodemográfica: primeiras aproximações. Revista Brasileira de Educação, Rio de Janeiro, v. 16, n. 48, p. 663-694, 2011. https://doi. org/10.1590/S1413-24782011000300008

TRAGTENBERG, M. A escola como organização complexa. Educação \& Sociedade, Campinas, v. 39, n. 142, p. 183-202, jan. 2018. https://doi.org/10.1590/es0101-73302018191196

UNESCO. Distance learning strategies in response to COVID-19 school closures. UNESCO COVID-19 Education Response. Education Sector issue notes. Issue note n. 2.1. Paris: UNESCO, Apr. 2020a.

UNESCO. Adverse consequences of school closures. COVID-19 Educational Disruption and Response. Paris: UNESCO, 2020b.

WASSERMAN, N.; HOLBERT, N.; BLIKSTEIN, P. Will the coronavirus infect education, too? The risk of a radical shift to online learning after the crisis ends. New York Daily News, 8 Apr 2020. Disponível em: https://www. nydailynews.com/opinion/ny-oped-coroanvirus-infect-education-20200408-tasi4zfbozcxlgq34f22rk4zwmstory.html. Acesso em: 14 maio 2020.

\section{Sobre os Autores:}

Luana Costa Almeida é professora adjunta do quadro efetivo da Universidade Federal de São Carlos (UFSCar) junto ao Departamento de Teorias e Práticas Pedagógicas (DTPP). Doutora em Educação pela Universidade Estadual de Campinas (Unicamp). Pesquisadora colaboradora no Laboratório de Observação e Estudos Descritivos (LOED) da Faculdade de Educação da Unicamp. Estuda a organização do trabalho pedagógico a partir da relação escola-entorno social, desigualdades educacionais e processos de avaliação educacional.

Adilson Dalben é consultor externo da Interação Urbana. Pesquisador colaborador do LOED (Laboratório de Observação e Estudos Descritivos). Professor colaborador do PRAPEM (Grupo de Pesquisa Prática Pedagógica em Matemática). Membro do Grupo de Formação e Pesquisa sobre o Conhecimento Interpretativo e Especializado do Professor que Ensina Matemática. Mestre e Doutor em Educação pela Universidade Estadual de Campinas (Unicamp).

Recebido: 17 jun. 2020

Aprovado: 14 out. 2020 